\title{
Efeitos dos Níveis de Fibra e de Fontes de Proteínas sobre a Concentração do Nitrogênio Amoniacal e pH Ruminal em Novilhos ${ }^{1}$
}

\author{
Alecssandro Regal Dutra², Augusto César de Queiroz ${ }^{3}$, José Tarcísio Lima Thiébaut ${ }^{3}$, Leôncio \\ Gonçalves Dutra ${ }^{2}$, Roberto de Camargo Wascheck ${ }^{2}$, Paulo César Moreira ${ }^{2}$
}

\begin{abstract}
RESUMO - O experimento foi conduzido com o objetivo de estudar os efeitos dos níveis de fibra (38,7 e 57,2\% de fibra em detergente neutro - FDN), compostos pela associação da silagem de capim-elefante com cana-de-açúcar in natura picada e das fontes de proteína, sendo uma de alta (farelo de soja) e outra de baixa (farelo de glúten de milho associado com farinha

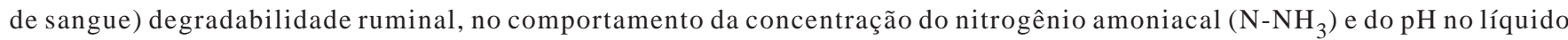
ruminal de novilhos, com predominância da raça Pardo-Suíça, fistulados no rúmen, com peso médio inicial de 316 kg, distribuídos em quadrado latino 4 x 4, alimentados ad libitum, individualmente. As maiores concentrações médias de N$\mathrm{NH}_{3}$ no líquido ruminal foram encontradas com as rações que utilizaram o farelo de soja como fonte de proteína, independentemente do nível de fibra em que foi encontrado o valor de $0,18 \mathrm{mg}$ de $\mathrm{N}-\mathrm{NH}_{3} / \mathrm{mL}$ de líquido ruminal. Os valores mínimos de $\mathrm{N}-\mathrm{NH}_{3}$ no líquido ruminal foram adequados ao crescimento microbiano em todas as rações experimentais. O menor valor médio de pH no líquido ruminal $(6,27)$ foi encontrado em rações com baixa fibra, e os valores mínimos de pH no líquido ruminal estiveram na faixa desejada para que ocorresse máximo crescimento microbiano, bem como digestão ruminal, em todas as rações experimentais.
\end{abstract}

Palavras-chave: concentração, fibra, fontes, níveis, nitrogênio amoniacal, proteína, pH, novilhos

\section{Effects of Fiber Levels and Protein Sources on the Ammonia Nitrogen Concentration and Ruminal pH in Steers}

\begin{abstract}
The experiment was carried out to study the effects of fiber levels (38.7 and 57.2\% NDF), composed of elephantgrass silage and chopped sugarcane and two protein sources, a high (soybean meal) and low (blood meal and corn glúten meal) ruminal degradable protein, on the ammonia nitrogen concentration $\left(\mathrm{N}-\mathrm{NH}_{3}\right)$ and on the ruminal $\mathrm{pH}$ of steers. Four rumen fistulated Brow-Swiss steers, with $316 \mathrm{~kg}$ of average initial weight, were randomly allotted to a 4 x 4 Latin square design. The steers were full fed diets containing two levels of fiber and two sources of protein with different ruminal degradable protein. The highest means of $\mathrm{N}^{-\mathrm{NH}_{3}}$ concentrations in the ruminal fluid were observed with the diets with soybean meal as protein source, independently of the fiber level, with values of 0.18 mg of $\mathrm{N}-\mathrm{NH}_{3} / \mathrm{mL}$ of ruminal fluid. The minimum values of $\mathrm{N}-\mathrm{NH}_{3}$ in the ruminal fluid were appropriate to the microbial growth in all the experiment diets. The smallest mean of $\mathrm{pH}$ value in the ruminal fluid was observed in diets with low fiber, with value of 6.27 , and the minimum value of $\mathrm{pH}$ in the ruminal fluid was in the range of maximum microbial growth, as well as maximum ruminal digestion, in all the experimental diets.
\end{abstract}

Key Words: concentration, fiber, levels, nitrogen ammonia, protein, $\mathrm{pH}$, sources, steers

\section{Introdução}

A concentração de amônia no rúmen é função da produção e remoção da mesma. A amônia entra no rúmen por diversas fontes, como a fermentação de alimentos, os fragmentos de células lisadas, as proteínas endógenas, os micelâneos de compostos de nitrogênio (N) solúveis (como uréia endógena, ácidos nucléicos, ácido úrico e nitratos) e a excreção protozoal. $\mathrm{O} \mathrm{N}-\mathrm{NH}_{3}$ é removido do rúmen por diversos caminhos, como a incorporação na matéria microbiana, que sai do rúmen, absorção por intermédio da parede ruminal e no fluido, escoando para os próximos segmentos do trato digestivo (Forbes \& France, 1993).

Quando proteínas com baixa degradabilidade ruminal são fornecidas, a quantidade de nitrogênio não-protéico necessária aumenta, pois menos proteína

\footnotetext{
${ }^{1}$ Parte da Tese apresentada à Universidade Federal de Viçosa pelo primeiro autor para obtenção do título de "Magister Scientiae" em Zootecnia.

2 Professores do Departamento de Zootecnia da Universidade Católica de Goiás (UCG). E.mail: lager@ucg.br

3 Professores da Universidade Federal de Viçosa (UFV).
} 
da ração é degradada à amônia no rúmen. Aumentos nas quantidades de proteínas com baixa degradabilidade ruminal fornecidas não asseguram aumentos na produção animal, visto que estas proteínas podem ser pobremente digeridas no intestino delgado; o balanço de aminoácidos da proteína pósruminal pode ser pobre ou o suprimento de energia ou outros nutrientes, além dos aminoácidos, podem limitar a produção animal (NRC, 1984).

O suprimento de amônia pode ser inadequado quando o consumo de proteína ou a degradação ruminal da proteína for baixo. A deficiência de amônia no rúmen reduz a eficiência do crescimento microbiano e pode reduzir a taxa e a extensão de digestão da matéria orgânica (MO) no rúmen, podendo, com isso, reduzir o consumo. Concentrações abaixo de $0,05 \mathrm{mg}$ de $\mathrm{N}-\mathrm{NH}_{3} / \mathrm{mL}$ de fluido ruminal não tem aumentado a produção de proteína microbiana, no entanto, altas concentrações podem aumentar tanto o pH quanto a digestão de MO (NRC, 1984; Church, 1988; Christensen et al., 1993; McDonald et al., 1993).

Segundo Kaufmann (1979), citado por Rodriguez (1986), toda a proteína em excesso, ao entrar no rúmen e ser degradada, será perdida como amônia. À medida que os requisitos de proteína aumentam, em função da maior produção, elevam-se também as perdas de proteína, sob a forma de amônia, se for mantida a mesma degradabilidade. A situação torna-se mais crítica se houver déficit de energia na ração.

Níveis de amônia no rúmen maiores que 0,08 a $0,15 \mathrm{mg}$ de $\mathrm{N}-\mathrm{NH}_{3} / \mathrm{mL}$ são requeridos para máxima digestão da MO no rúmen de vacas em lactação. Maiores digestibilidades de matéria seca (MS) são observadas quando a amônia ruminal é maior que 0,05 $\mathrm{mg} / \mathrm{mL}$ (Van Soest, 1982). Segundo Russell et al. (1992) e Forbes \& France (1993), a maioria das espécies bacterianas utiliza a amônia para crescimento, e para algumas espécies a amônia é essencial. Dependendo da ração, 40 a 95\% do N nas bactérias são derivados da amônia, sendo o restante vindo de peptídeos e aminoácidos.

Titgemeyer et al. (1989), trabalhando com fontes de proteína com diferentes degradabilidades ruminais, ou seja, farelo de soja, farelo de glúten de milho e farinha de sangue, encontraram produção de $\mathrm{N}-\mathrm{NH}_{3}$ em mg/dL de líquido ruminal de 39,78, 23,04 e 16,16, respectivamente, tendo Robinson \& McQueen (1994) também encontrado valores maiores para o farelo de soja (91,9 mg/L) em comparação com o farelo de glúten de milho associado à farinha de sangue $(80,4 \mathrm{mg} / \mathrm{L})$.

Cecava et al. (1990) encontraram resultados de similaridade na produção de $\mathrm{N}-\mathrm{NH}_{3}$ no rúmen de novilhos da raça Simental, fornecendo duas rações com diferentes teores de fibra, obtendo valor médio de $0,179 \mathrm{mg}$ de $\mathrm{N}-\mathrm{NH}_{3} / \mathrm{mL}$ de líquido ruminal.

Em outro trabalho, Cecava et al. (1991) mencionam que o nível de energia na ração não afetou a concentração de $\mathrm{N}-\mathrm{NH}_{3}(\mathrm{mg} / \mathrm{mL})$ e a taxa de produção total ruminal (g/dia), tendo média de $0,157 \mathrm{mg} / \mathrm{mL}$ e 129,5 g/dia, respectivamente. Com relação à fonte de proteína, fornecendo farelo de soja em comparação ao farelo de glúten de milho associado à farinha de sangue, a concentração de $\mathrm{N}-\mathrm{NH}_{3}(\mathrm{mg} / \mathrm{mL})(0,18 \mathrm{vs}$ $0,135)$ e a produção total de $\mathrm{N}-\mathrm{NH}_{3}$ ruminal (g/dia) $(141,6$ vs 117,4$)$ foram aumentadas e 68 e $55 \%$ do nitrogênio da ração passaram pelo “pool” de $\mathrm{N}-\mathrm{NH}_{3}$, respectivamente.

$\mathrm{O}$ pH é influenciado pelo tipo de alimentação consumida e sua estabilização é devida em grande parte à saliva, que possui alto poder tamponante. A propriedade da mucosa do rúmen de absorver mais rapidamente os ácidos livres que os combinados, resultantes da fermentação, representa outro fator que contribui para impedir a acidificação do meio, a qual influenciará negativamente as atividades dos microrganismos (Coelho da Silva \& Leão, 1979). As bactérias do rúmen são adaptadas para se desenvolverem em um meio com pH de 5,5 a 7,0 (Coelho da Silva \& Leão, 1979 e Hoover \& Stokes, 1991). Segundo Church (1988), o pH ruminal exerce importante efeito na determinação da concentração de amônia no rúmen.

Em situações de pH abaixo de 6,2, ocorrerá redução na digestão de fibra, já que as bactérias celulolíticas são sensíveis a pH inferior a 6,2 (Orskov, 1988; Cecava et al., 1990), ocorrendo na faixa de 6,7 a 7,1 o ponto ótimo para a digestão da fibra. Um $\mathrm{pH}$ reduzido diminui a digestão de proteínas, celulose, hemicelulose e pectinas, tendo menor efeito na digestão do amido, enquanto $\mathrm{pH}$ na faixa de 6,5 a 5,5 também causa decréscimo na eficiência microbiana (Hoover \& Stokes, 1991).

Shriver et al. (1986), trabalhando com rações contendo $65 \%$ de concentrado e $35 \%$ de forragem, obtiveram resultados de redução na digestibilidade da MO, da fibra em detergente neutro (FDN) $(8,1 \%)$ e do $\mathrm{N}$ em pH de 5,8, enquanto em $\mathrm{pH}$ de 6,2 ocorreu marcante aumento na digestibilidade da MO, da FDN

R. Bras. Zootec., v.33, n.3, p.714-722, 2004 
$(33,1 \%)$ e dos compostos nitrogenados. Para $\mathrm{pH}$ variando de 6,2 a 7,0, o aumento na digestibilidade desses ingredientes foi pouco significativo. A atividade celulolítica decresceu marcadamente quando o $\mathrm{pH}$ foi reduzido de 6,5 para 5,5. A concentração de $\mathrm{N}-\mathrm{NH}_{3}$ ruminal também foi reduzida drasticamente (26,3 para 3,8 mg/dL) com a redução do $\mathrm{pH}$ (7,0 para $5,8)$, afetando negativamente a digestão da fibra. A eficiência microbiana foi maior para $\mathrm{pH}$ de 5,8 e decresceu para $\mathrm{pH}$ de 7,0.

Titgemeyer et al. (1989), trabalhando com fontes de proteína com diferentes degradabilidades ruminais, ou seja, farelo de soja, farelo de glúten de milho e farinha de sangue, não encontraram efeito da fonte de proteína nos valores médios de $\mathrm{pH}$ ruminal, obtendo resultado de 6,24, o que também foi observado por Robinson \& McQueen (1994) trabalhando com farelo de soja $(6,17)$ e farelo de glúten de milho associado à farinha de sangue $(6,19)$.

Cecava et al. (1990) encontraram valores médios de $\mathrm{pH}$ de 6,46 e 5,71 para rações com alta e baixa fibra, respectivamente. Posteriormente, Cecava et al. (1991) também mencionaram decréscimo no pH ruminal, à medida que se aumentou a proporção de concentrado na ração, obtendo valores médios de 6,10 e 5,86 para as rações com alta e baixa fibra, respectivamente, e de 6,00 e 5,97 para as rações que continham farelo de soja e farelo de glúten de milho associado à farinha de sangue, respectivamente, podendo-se observar que a fonte de proteína teve pouco efeito no valor médio do $\mathrm{pH}$ ruminal.

A amônia é absorvida por meio da parede do rúmen, estritamente por difusão passiva, e a quantidade absorvida está positivamente relacionada às concentrações ruminais de amônia e ao pH. A amônia livre difunde, por intermédio das membranas das células, mais rapidamente que o $\mathrm{NH}_{4}^{+}$, conseqüentemente, maiores taxas de absorção ocorrem em maior $\mathrm{pH}$, em virtude da maior concentração de $\mathrm{NH}_{3}$ livre. Taxas de transporte de $\mathrm{NH}_{3}$ por meio da parede do rúmen, por exemplo, são três vezes maiores para pH 6,5 que para 4,5 (Church, 1988; Forbes \& France, 1993).

O objetivo deste trabalho foi estudar os principais efeitos da proporção volumoso:concentrado, utilizando-se dois níveis de fibra e duas fontes de proteína, sendo uma de alta e outra de baixa degradabilidade ruminal, sobre o comportamento da concentração do $\mathrm{N}-\mathrm{NH}_{3}$ e do $\mathrm{pH}$ no líquido ruminal, em novilhos.

\section{Material e Métodos}

O experimento foi conduzido nas dependências do Laboratório Animal do Departamento de Zootecnia do Centro de Ciências Agrárias da Universidade Federal de Viçosa (UFV), em Viçosa, MG.

Foram utilizados no experimento quatro novilhos, com predominância da raça Pardo-Suíça, castrados, com peso médio de $316 \mathrm{~kg}$ e idade variando entre 24 e 36 meses.

Os animais foram submetidos a intervenções cirúrgicas, para a implantação de cânulas no rúmen, segundo técnica descrita por Leão \& Coelho da Silva (1980). Os animais foram submetidos a quatro períodos experimentais com duração de 22 dias cada, sendo 14 dias de adaptação às rações e oito de coletas.

Foram utilizadas quatro rações experimentais à base de cana-de-açúcar (Saccharum officinarum L.) in natura picada, silagem de capim-elefante (Pennisetum purpurem L.) e grão de milho (Zea mays L.) moído. As rações com alta e baixa fibra (FDN) foram calculadas para uma taxa de ganho de peso vivo médio diário provável de 700 e 1000 g, respectivamente. Os suplementos de proteína utilizados foram o farelo de soja e a combinação de farelo de glúten de milho com farinha de sangue. Essas fontes de proteína são representativas da proteína mais e menos prontamente degradáveis no rúmen, respectivamente. As rações foram calculadas e balanceadas de acordo com o NRC (1989).

Para separar os efeitos da concentração de amônia e da degradabilidade ruminal da proteína nas análises mensuradas, as dietas foram formuladas objetivando proporcionar suprimento teórico de concentrações adequadas de amônia para síntese máxima de proteína microbiana. A uréia foi incluída no teor de 0,7\% na MS das rações, com esse propósito.

A proporção dos ingredientes utilizados nas rações e os teores de MS, MO, proteína bruta (PB), carboidratos totais (CHT), extrato etéreo (EE), fibra em detergente neutro (FDN) e minerais (MM) das quatro rações experimentais constam nas Tabelas 1 e 2. Os teores de MS, MO, PB, CHT, EE, FDN e MM dos concentrados e dos volumosos utilizados na formulação das rações experimentais encontram-se na Tabela 3.

As rações foram fornecidas ad libitum, individualmente, às $9 \mathrm{~h}$, sendo controlado diariamente $\mathrm{o}$ consumo, procurando-se manter as sobras entre $10 \mathrm{e}$ $20 \%$ do total fornecido. Realizaram-se coletas de 
alimentos oferecidos e sobras destes alimentos durante todos os períodos de coletas, em todos os animais.

Amostras dos alimentos oferecidos diariamente e das sobras foram coletadas do $14^{\circ}$ ao $22^{\circ}$ dia de cada período experimental, obtendo-se, ao final de cada um desses períodos, amostras compostas das sobras e dos alimentos por animal. Todas as amostras foram armazenadas em sacos plásticos identificados e colocadas em congelador a $-10^{\circ} \mathrm{C}$, para que, em seguida, fossem descongeladas e processadas.

Coletaram-se amostras de aproximadamente $50 \mathrm{~mL}$ do líquido ruminal no $21^{\circ}$ e $22^{\circ}$ dia de cada período experimental, a 1, 2, 4, 6, 8, 12 e 24 horas após o fornecimento das rações, sendo acondicionadas individualmente (por animal, por período) em recipiente de vidro com tampa de polietileno. Imediatamente após a coleta, determinou-se o valor de $\mathrm{pH}$ e, logo em seguida, foram acidificadas com $3 \mathrm{~mL}$ de $\mathrm{HCl} 6 \mathrm{~N}$ e congeladas a $-10^{\circ} \mathrm{C}$. Posteriormente, as amostras foram descongeladas à temperatura ambiente e processadas, para determinaçao das concentrações de $\mathrm{N}-\mathrm{NH}_{3}$.

As análises foram realizadas no Laboratório de Nutrição Animal do Departamento de Zootecnia da Universidade Federal de Viçosa. As análises de MS, MO, PB, EE, FDN e MM, feitas para os alimentos fornecidos, foram conduzidas segundo metodologias descritas por Silva (1990). Os teores de CHT dos alimentos oferecidos foram determinados segundo metodologia da Universidade de Cornell, descrita por Sniffen et al. (1992), em que CHT = $100-(\%$ PB + $\% \mathrm{EE}+\% \mathrm{MM})$. A concentração de nitrogênio amoniacal foi determinada em extrato obtido por centrifugação das amostras a 3000 rpm, destilando-se alíquotas de $2 \mathrm{~mL}$ do extrato com $5 \mathrm{~mL}$ de $\mathrm{KOH}$ 0,05N e titulando com ácido clorídrico.

O experimento foi conduzido segundo o desenho fatorial 2 x 2 (dois níveis de fibra $\mathrm{x}$ duas fontes de proteína), sendo os principais fatores a proporção volumoso:concentrado (nível de fibra) e a fonte suplementar de proteína nas rações, no delineamento

Tabela 1 - Composição das rações experimentais

Table 1 - Composition of the experimental diets

\begin{tabular}{|c|c|c|c|c|}
\hline \multirow{2}{*}{$\begin{array}{l}\text { Ingredient (\%MS) } \\
\text { Ingredient (\%DM) }\end{array}$} & \multicolumn{4}{|c|}{$\begin{array}{l}\text { Dieta } \\
\text { Diet }\end{array}$} \\
\hline & $\begin{array}{l}\text { BF-FSo } \\
\text { LF-SBM }\end{array}$ & $\begin{array}{c}\text { BF-FGM/FSa } \\
L F-C G M / B M\end{array}$ & $\begin{array}{l}\text { AF-FSo } \\
\text { HF-SBM }\end{array}$ & $\begin{array}{c}\text { AF-FGM/Fsa } \\
H F-C G M / B M\end{array}$ \\
\hline $\begin{array}{l}\text { Cana-de-açúcar } \\
\text { Sugarcane }\end{array}$ & 23,8 & 23,0 & 36,9 & 42,1 \\
\hline $\begin{array}{l}\text { Sil. capim-elefante } \\
\text { Elephantgrass silage }\end{array}$ & 21,8 & 20,9 & 40,6 & 41,3 \\
\hline $\begin{array}{l}\text { Grão de milho } \\
\text { Corn grain }\end{array}$ & 37,2 & 43,1 & - & - \\
\hline $\begin{array}{l}\text { Farelo de soja } \\
\text { Soybean meal }\end{array}$ & 11,6 & - & 16,9 & - \\
\hline $\begin{array}{l}\text { Farinha de sangue } \\
\text { Blood meal }\end{array}$ & - & 1,6 & - & 5,2 \\
\hline $\begin{array}{l}\text { F. glúten de milho } \\
\text { Corn gluten meal }\end{array}$ & - & 5,8 & - & 5,8 \\
\hline $\begin{array}{l}\text { Melaço } \\
\text { Molasses }\end{array}$ & 3,0 & 3,0 & 3,0 & 3,0 \\
\hline $\begin{array}{l}\text { Uréia } \\
\text { Urea }\end{array}$ & 0,7 & 0,7 & 0,7 & 0,7 \\
\hline $\begin{array}{l}\text { Fosfato bicálcico } \\
\text { Dicalcium phosphate }\end{array}$ & 1,6 & 1,6 & 1,6 & 1,6 \\
\hline $\begin{array}{l}\text { Sal } \\
\text { Salt }\end{array}$ & 0,3 & 0,3 & 0,3 & 0,3 \\
\hline $\begin{array}{l}\text { Vol./Conc. } \\
\text { For./Con. ratio } \\
\end{array}$ & $45,5 / 54,5$ & 43,9/56,1 & $77,5 / 22,5$ & $83,4 / 16,6$ \\
\hline
\end{tabular}

R. Bras. Zootec., v.33, n.3, p.714-722, 2004 
quadrado latino $4 \times 4$ (quatro animais x quatro períodos), segundo Gomes (1990), no modelo estatístico:

$$
\mathrm{Y}_{\mathrm{i}(\mathrm{j})}=\mu+\mathrm{P}_{\mathrm{i}}+\mathrm{F}_{\mathrm{i}},+\left(\mathrm{P}_{\mathrm{i}}+\mathrm{F}_{\mathrm{i}}\right)+\mathrm{A}_{\mathrm{j}}+\mathrm{P}_{\mathrm{k}}+\mathrm{e}_{\mathrm{i}(\mathrm{j} \mathrm{k})}
$$

em que $\mathrm{Y}_{\mathrm{i}(\mathrm{k})}=$ variável estudada no animal $\mathrm{j}$, no período $k$, referente ao tratamento ii'; $\mu$ = efeito da media geral; $\mathrm{P}_{\mathrm{i}}=$ efeito da fonte de proteína no tratamento ii'; $\mathrm{F}_{\mathrm{i}}$, = nível de fibra no tratamento ii'; $\left(P_{i}+F_{i}\right)=$ efeito da interação entre fonte de proteína e nível de fibra no tratamento ii'; $A_{j}=$ efeito do animal j no tratamento ii'; $\mathrm{P}_{\mathrm{k}}=$ efeito do período k no tratamento ii'; $\mathrm{e}_{\mathrm{i}(\mathrm{k})}=$ variável aleatória normal e independente distribuída com média zero e variância $\delta^{2}$.

Os dados experimentais foram analisados utilizando-se o programa SAEG - Sistema de Análise Estatísticas e Genéticas (UFV, 1995), estudando-se o efeito do tempo na subparcela e nas determinações das concentrações de nitrogênio amoniacal e pH no líquido ruminal.

\section{Resultados e Discussão}

As equações de regressão ajustadas para as concentrações de $\mathrm{N}_{-} \mathrm{NH}_{3}$ no líquido ruminal, em função do tempo, para as rações experimentais, constam na Tabela 4.

Os comportamentos das concentrações do $\mathrm{N}-\mathrm{NH}_{3}$ no rúmen, em função dos tempos de coleta, para as rações experimentais, são demonstrados na Figura 1.

Os valores das concentrações médias do $\mathrm{N}-\mathrm{NH}_{3}$ no líquido ruminal, em função dos tempos de coleta, são apresentados na Tabela 5.

O nível de forragem na ração não afetou $(\mathrm{P}>0,05)$ a concentração de $\mathrm{N}-\mathrm{NH}_{3}$ ruminal e a fonte de proteína, de alta ou baixa degradabilidade ruminal, exerceu influência $(\mathrm{P}<0,05)$ nessa concentração.

Pode-se observar também que o pico máximo de concentração de $\mathrm{N}-\mathrm{NH}_{3}$, calculado por intermédio das equações de regressão demonstradas na Tabela 4,

Tabela 2 - Composição de nutrientes das rações experimentais

Table 2 - Nutrient composition of the experimental diets

\begin{tabular}{|c|c|c|c|c|}
\hline \multirow{2}{*}{$\begin{array}{l}\text { Nutriente (\%MS) } \\
\text { Nutrient (\%DM) }\end{array}$} & \multicolumn{4}{|c|}{$\begin{array}{l}\text { Dieta } \\
\text { Diet }\end{array}$} \\
\hline & $\begin{array}{l}\text { BF-FSo } \\
L F-S B M\end{array}$ & $\begin{array}{c}\text { BF-FGM/FSa } \\
L F-C G M / B M\end{array}$ & $\begin{array}{l}\text { AF-FSo } \\
H F-S B M\end{array}$ & $\begin{array}{l}\text { AF-FGM/Fsa } \\
H F-C G M / B M\end{array}$ \\
\hline $\begin{array}{l}\text { Matéria seca } \\
\text { Dry matter }\end{array}$ & 52,46 & 53,36 & 40,93 & 39,31 \\
\hline $\begin{array}{l}\text { Matéria orgânica } \\
\text { Organic matter }\end{array}$ & 94,99 & 95,24 & 93,74 & 94,05 \\
\hline $\begin{array}{l}\text { Proteína bruta } \\
\text { Crude protein }\end{array}$ & 10,67 & 11,39 & 11,96 & 12,15 \\
\hline $\begin{array}{l}\text { PDR/PNDR } \\
R D P / R N D P\end{array}$ & $2,4 / 1,0$ & $1,2 / 1,0$ & $3,8 / 1,0$ & $0,8 / 1,0$ \\
\hline $\begin{array}{l}\text { Carboidrato total } \\
\text { Total carbohydrate }\end{array}$ & 82,91 & 82,62 & 80,93 & 81,04 \\
\hline $\begin{array}{l}\text { NDT } \\
N D T\end{array}$ & 52,83 & 53,55 & 42,14 & 38,74 \\
\hline $\begin{array}{l}\text { Extrato etéreo } \\
\text { Ether extract }\end{array}$ & 1,41 & 1,23 & 0,85 & 0,86 \\
\hline $\begin{array}{l}\text { FDN } \\
N D F\end{array}$ & 39,51 & 37,87 & 55,32 & 59,06 \\
\hline $\begin{array}{l}\text { Minerais } \\
\text { Minerals }\end{array}$ & 5,01 & 4,76 & 6,26 & 5,95 \\
\hline $\begin{array}{l}\mathrm{BF}=\text { baixa fibra; } \mathrm{AF}= \\
\text { com farinha de sang } \\
\text { FDN = fibra em dete } \\
\mathrm{PDR}=\text { proteína degr } \\
\mathrm{NDT}=\text { nutrientes dig } \\
\mathrm{LF}=\text { low fiber; } \mathrm{HF}=\text { hig } \\
\text { NDF = Neutral detergen } \\
R D P=\text { Rumen degradab } \\
\text { NDT = total digestible }\end{array}$ & $\begin{array}{l}\mathrm{ra} ; \mathrm{FSo}=\mathrm{fa} \\
\text { neutro. } \\
\text { no rúmen e } \\
\text { S totais. } \\
\text { SBM = soybe } \\
\text { n and RUDP }\end{array}$ & $\begin{array}{l}\text { de soja; FGM/FS } \\
\text { DR = proteína nã } \\
\text { eal; CGM/BM = col } \\
\text { nen undegradable }\end{array}$ & $\begin{array}{l}\text { relo de glút } \\
\text { gradável nc } \\
\text { ten meal ass }\end{array}$ & $\begin{array}{l}\text { milho associado } \\
\text { ed to blood meal. }\end{array}$ \\
\hline
\end{tabular}

R. Bras. Zootec., v.33, n.3, p.714-722, 2004 
ocorreu de uma a duas horas após o fornecimento para as rações com baixa fibra e uma a quatro horas após o fornecimento para as rações com alta fibra. As rações que continham farelo de soja em sua composição apresentaram sempre concentração maior de $\mathrm{N}-\mathrm{NH}_{3}$ ruminal.

As concentrações médias de $\mathrm{N}-\mathrm{NH}_{3}$ no líquido ruminal para todas as rações (Tabela 5) estiveram acima do mínimo requerido para máximo crescimento microbiano e máxima digestão ruminal que, segundo Slyter et al. (1979), NRC (1984), Church (1988), Christensen et al. (1993) e McDonald et al. (1993), é de 5 mg/100 mL. A concentração mínima para todas as rações, calculada por intermédio das equações de regressão demonstradas na Tabela 4, também foi superior. Isso pode ter proporcionado condições para que ocorresse semelhança na eficiência de síntese microbiana entre todas as rações.

Os valores mais elevados de $\mathrm{N}-\mathrm{NH}_{3}$ foram encontrados nas rações que utilizavam farelo de soja como fonte de proteína $\left(0,18 \mathrm{mg} \mathrm{N}-\mathrm{NH}_{3} / \mathrm{mL}\right.$ de líquido ruminal), independentemente do nível de fibra, podendo ser devido ao maior conteúdo de proteína bruta prontamente degradável no rúmen e à maior concentração de $\mathrm{N}-\mathrm{NH}_{3}$ no líquido ruminal com o farelo de soja, em comparação com o farelo de glúten de milho associado com farinha de sangue, o que

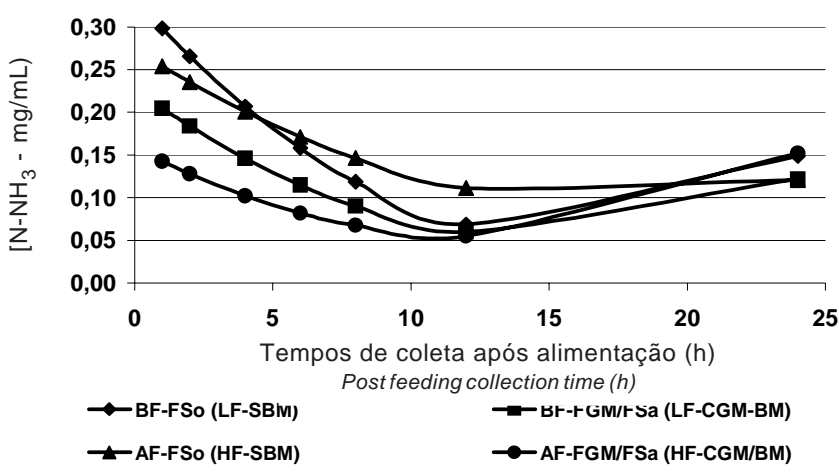

Figura 1 - Estimativas das concentrações de nitrogênio amoniacal no líquido ruminal, em função dos tempos de coleta, para as rações experimentais, em novilhos.

Figure 1 - Ammonia concentration estimates in the rumen fluid as function of the collection time for the experimental diets, in steers.

Tabela 3 - Proporção de matéria seca (MS), matéria orgânica (MO), proteína bruta (PB), carboidratos totais ( $\mathrm{CHT}$ ), extrato etéreo (EE), fibra em detergente neutro (FDN) e minerais dos concentrados e volumosos das rações experimentais

Table 3 - Proportion of dry matter (DM), organic matter (OM), crude protein (CP), total carbohydrate $(T C H)$, ether extract (EE), neutral detergent fiber (NDF) and minerals (MM) of the concentrates and forages of the experimental diets

\begin{tabular}{|c|c|c|c|c|c|c|c|}
\hline \multirow[t]{3}{*}{$\begin{array}{l}\text { Dieta } \\
\text { Diet }\end{array}$} & \multicolumn{7}{|c|}{$\begin{array}{l}\text { Proporção do nutriente } \\
\text { Nutrients proportion }\end{array}$} \\
\hline & MS & $\mathrm{MO}$ & PB & CHT & EE & FDN & MM \\
\hline & $D M$ & $O M$ & $C P$ & TCH & $E E$ & $N D F$ & $M M$ \\
\hline & \multicolumn{7}{|c|}{ Concentrado (\% MS) } \\
\hline $\begin{array}{l}\text { BF-FSo } \\
\text { LF-SBM }\end{array}$ & 89,10 & 94,19 & 17,33 & 74,85 & 2,01 & 17,03 & 5,81 \\
\hline $\begin{array}{l}\text { BF-FGM/Fsa } \\
L F-C G M-B M\end{array}$ & 89,08 & 94,67 & 18,20 & 74,81 & 1,66 & 15,56 & 5,33 \\
\hline $\begin{array}{l}\text { AF/FSo } \\
H F-S B M\end{array}$ & 89,28 & 86,51 & 43,69 & 41,45 & 1,37 & 13,51 & 13,49 \\
\hline $\begin{array}{l}\mathrm{AF}-\mathrm{FGM} / \mathrm{FSa} \\
\mathrm{HF-CGM/BM}\end{array}$ & 89,24 & 89,94 & 58,96 & 29,30 & 1,68 & 20,78 & 10,06 \\
\hline & \multicolumn{7}{|c|}{ Volumoso (\% MS) } \\
\hline $\begin{array}{l}\text { Cana-de-açúcar } \\
\text { Sugarcane }\end{array}$ & 33,51 & 97,38 & 1,70 & 95,21 & 0,47 & 56,49 & 2,62 \\
\hline $\begin{array}{l}\text { Sil. capim-elefante } \\
\text { Elephantgrass silage }\end{array}$ & 37,38 & 94,39 & 3,80 & 89,67 & 0,92 & 77,25 & 5,61 \\
\hline
\end{tabular}

R. Bras. Zootec., v.33, n.3, p.714-722, 2004 
também foi observado por Titgemeyer et al. (1989), Cecava et al. (1990) e Cecava et al. (1991).

As equações de regressão ajustadas para as leituras de $\mathrm{pH}$ no líquido ruminal, em função do tempo, para as rações experimentais constam na Tabela 6.

O comportamento do $\mathrm{pH}$ no líquido ruminal, em função dos tempos de coleta, para as rações experimentais, é demonstrado na Figura 2.

Os valores médios de pH no líquido ruminal, em função dos tempos de coleta, são apresentados na Tabela 7.

O nível de forragem na ração afetou $(\mathrm{P}<0,05)$ o $\mathrm{pH}$ ruminal; e a fonte de proteína, de alta ou baixa degradabilidade ruminal não teve efeito sobre o $\mathrm{pH}$ ruminal $(\mathrm{P}>0,05)$, semelhantemente ao observado por Titgemeyer et al. (1989), Cecava et al. (1990), Cecava et al. (1991) e Robinson \& McQueen (1994).

Os valores médios de $\mathrm{pH}$ ruminal para todas as rações estiveram na faixa aceitável para máximo crescimento microbiano e máxima digestão ruminal de fibras, que, segundo Coelho da Silva \& Leão (1979), Orskov (1988), Cecava et al. (1990) e Hoover \& Stokes (1991), está entre 5,5 e 7,0, estando a faixa ideal de pH para a digestão da fibra situada entre 6,7 e 7,1. O valor de $\mathrm{pH}$ mínimo para todas as rações também esteve dentro da faixa desejada (Tabela 6), podendo ter proporcionado condições para que ocorresse semelhança na eficiência de síntese microbiana e digestão da fibra entre todas as rações.

Os valores mais elevados de $\mathrm{pH}$ ruminal foram encontrados nas rações contendo farelo de glúten de milho associado à farinha de sangue como fonte de proteína (6,73 vs 6,53 para rações com baixa e alta fibra, respectivamente), podendo ser decorrentes menor conteúdo de proteína bruta prontamente degradável no rúmen em comparação com o farelo de soja, ocasionando menor fermentação ruminal.

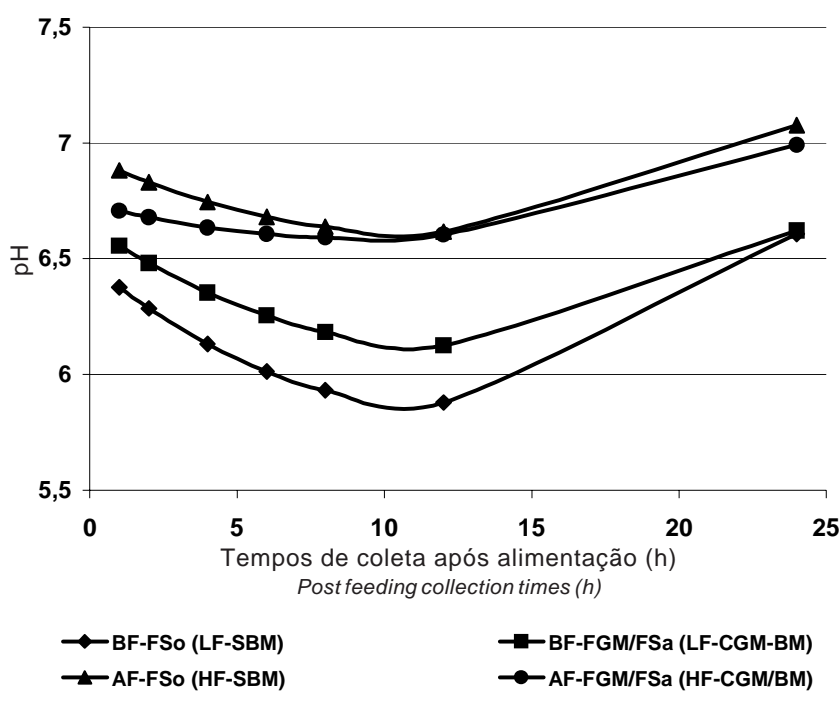

Figura 2 - Estimativas dos valores de $\mathrm{pH}$ no líquido ruminal, em função dos tempos de coleta, para as rações experimentais, em novilhos.

Figure 2 - $\mathrm{pH}$ value estimates in the rúmen fluid, as function of the collection times for the experimental diets, in steers.

Tabela 4 - Equações de regressão ajustadas para as concentrações de nitrogênio amoniacal $\left(\mathrm{N}-\mathrm{NH}_{3}\right)$ no líquido ruminal $(\mathrm{mg} / \mathrm{mL})$, em função dos tempos de coleta, em novilhos

Table 4 - Fitted regression equation for the ammonia nitrogen $\left(\mathrm{N}-\mathrm{NH}_{3}\right)$ concentration in the rumen fluid $(\mathrm{mg} / \mathrm{mL})$, as function of the collection time, in steers

\begin{tabular}{|c|c|}
\hline $\begin{array}{l}\text { Dieta } \\
\text { Diet }\end{array}$ & $\begin{array}{l}\text { Regressão } \\
\text { Regression }\end{array}$ \\
\hline BF-FSo & $\hat{\mathrm{Y}}=0,3336-0,0365 \mathrm{~T}+0,0012 \mathrm{~T}^{2}\left(\mathrm{R}^{2}=88,49\right)$ \\
\hline$L F-S B M$ & \\
\hline $\begin{array}{l}\text { BF-FGM/Fsa } \\
L F-C G M-B M\end{array}$ & $\hat{\mathrm{Y}}=0,2276-0,0236 \mathrm{~T}+0,0008 \mathrm{~T}^{2}\left(\mathrm{R}^{2}=80,03\right)$ \\
\hline $\begin{array}{l}\text { AF-FSo } \\
H F-S B M\end{array}$ & $\hat{Y}=0,2743-0,0208 T+0,0006 T^{2}\left(R^{2}=96,31\right)$ \\
\hline $\begin{array}{l}\text { AF-FGM/Fsa } \\
H F-C G M / B M\end{array}$ & $\hat{\mathrm{Y}}=0,1592-0,0171 \mathrm{~T}+0,0007 \mathrm{~T}^{2}\left(\mathrm{R}^{2}=96,51\right)$ \\
\hline
\end{tabular}

$\mathrm{BF}=$ baixa fibra; $\mathrm{AF}$ = alta fibra; FSo = farelo de soja; FGM/FSa = farelo de glúten de milho associado com farinha de sangue.

$L F=$ low fiber; $H F=$ high fiber; $S B M=$ soybean meal; $C G M / B M=$ corn gluten meal associated to blood meal.

R. Bras. Zootec., v.33, n.3, p.714-722, 2004 
Tabela 5 - Concentrações médias de nitrogênio amoniacal $\left(\mathrm{N}-\mathrm{NH}_{3}\right)(\mathrm{mg} / \mathrm{mL})$ no líquido ruminal das rações experimentais, em novilhos

Table 5 - Ammonia nitrogen $\left(\mathrm{N}_{-} \mathrm{NH}_{3}\right)$ concentration mean $(\mathrm{mg} / \mathrm{mL})$ in the rumen fluid of the experimental diets, in steers

\begin{tabular}{|c|c|c|c|c|}
\hline \multirow[t]{3}{*}{ Item } & \multicolumn{4}{|c|}{$\begin{array}{c}\text { Concentrações médias de } \mathrm{N}-\mathrm{NH}_{3} \text { no líquido ruminal } \\
\mathrm{N}-\mathrm{NH}_{3} \text { concentration mean in the rumen fluid }\end{array}$} \\
\hline & \multicolumn{2}{|c|}{$\begin{array}{l}\text { Nível de fibra } \\
\text { Fiber level }\end{array}$} & \multicolumn{2}{|c|}{$\begin{array}{c}\text { Fonte de proteína } \\
\text { Protein source }\end{array}$} \\
\hline & $\begin{array}{l}\mathrm{BF} \\
L F\end{array}$ & $\begin{array}{l}\mathrm{AF} \\
\mathrm{HF}\end{array}$ & $\begin{array}{l}\text { FSo } \\
\text { SBM }\end{array}$ & $\begin{array}{l}\text { FGM/FSa } \\
C G M / B M\end{array}$ \\
\hline $\mathrm{N}-\mathrm{NH}_{3}$ & 0,16 & 0,14 & $0,18^{a}$ & $0,12^{\mathrm{b}}$ \\
\hline
\end{tabular}

$\mathrm{BF}=$ baixa fibra; $\mathrm{AF}$ = alta fibra; FSo = farelo de soja; FGM/FSa = farelo de glúten de milho associado com farinha de sangue.

$L F=$ low fiber; $H F=$ high fiber; $S B M=$ soybean meal; $C G M / B M=$ corn gluten meal associated to blood meal.

Dentro de níveis de fibra e de fontes de proteína, médias seguidas de letras diferentes, na linha, são diferentes entre si $(P<0,05)$, pelo teste $F$.

Within fiber levels and protein sources, means followed by different letters, within a row, differ $(P<.05)$ by $F$ test.

Tabela 6 - Equações de regressão ajustadas para os valores de $\mathrm{pH}$ no líquido ruminal, em função dos tempos de coleta, em novilhos

Table 6 - Fitted regression equations for $\mathrm{pH}$ values in the rumen fluid as function of the collection times, in steers

\begin{tabular}{lc}
$\begin{array}{l}\text { Ração } \\
\text { Diet }\end{array}$ & $\begin{array}{c}\text { Regressão } \\
\text { Regression }\end{array}$ \\
\hline $\begin{array}{l}\text { BF-FSo } \\
\text { F-SBM }\end{array}$ & $\hat{\mathrm{Y}}=6,4773-0,1050 \mathrm{~T}+0,0046 \mathrm{~T}^{2}\left(\mathrm{R}^{2}=92,72\right)$ \\
$\begin{array}{l}\text { BF-FGM/FSa } \\
\text { LF-CGM-BM }\end{array}$ & $\hat{\mathrm{Y}}=6,6365-0,0846 \mathrm{~T}+0,0035 \mathrm{~T}^{2}\left(\mathrm{R}^{2}=97,08\right)$ \\
AF-FSo & $\hat{\mathrm{Y}}=6,9368-0,0590 \mathrm{~T}+0,0027 \mathrm{~T}^{2}\left(\mathrm{R}^{2}=78,69\right)$ \\
HF-SBM & $\hat{\mathrm{Y}}=6,7364-0,0326 \mathrm{~T}+0,0018 \mathrm{~T}^{2}\left(\mathrm{R}^{2}=84,60\right)$ \\
AF-FGM/FSa & \\
HF-CGM/BM &
\end{tabular}

$\mathrm{BF}=$ baixa fibra; $\mathrm{AF}=$ alta fibra; $F \mathrm{So}=$ farelo de soja; $F G M / F S a=$ farelo de glúten de milho associado com farinha de sangue.

$L F=$ low fiber; $H F=$ high fiber; $S B M=$ soybean meal; $C G M / B M=$ corn gluten meal associated with blood meal.

Tabela 7 - Valores médios de pH no líquido ruminal nas rações experimentais, em novilhos

Table $7-\quad p H$ value means in the rumen fluid of the experimental diets, in steers

Item Valores médios de $\mathrm{pH}$ no líquido ruminal $\mathrm{pH}$ value means in the rumen fluid

\begin{tabular}{ccccc} 
& \multicolumn{2}{c}{ Nível de fibra } & \multicolumn{2}{c}{$\begin{array}{c}\text { Fonte de proteína } \\
\text { Protein source }\end{array}$} \\
\cline { 2 - 5 } & $\mathrm{BF}$ & $\mathrm{AF}$ & Fso & FGM/FSa \\
& $L F$ & $H F$ & $S B M$ & $C G M / B M$ \\
\hline $\mathrm{pH}$ & $6,27^{\mathrm{b}}$ & $6,73^{\mathrm{a}}$ & 6,48 & 6,53 \\
\hline
\end{tabular}

$\overline{\mathrm{BF}}$ = baixa fibra; $\mathrm{AF}$ = alta fibra; FSo = farelo de soja; FGM/FSa = farelo de glúten de milho associado com farinha de sangue.

$L F=$ low fiber; $H F=$ high fiber; $S B M=$ soybean meal; $C G M / B M=$ corn gluten meal associated to blood meal.

Dentro de níveis de fibra e de fontes de proteína, médias seguidas de letras diferentes, na linha, são diferem entre si $(P<0,05)$, pelo teste $F$.

Within fiber levels and protein sources, means followed by different letters, within a row, differ $(P<.05)$ by $F$ test. 


\section{Conclusões}

As maiores concentrações de nitrogênio amoniacal $\left(\mathrm{N}-\mathrm{NH}_{3}\right)$ no líquido ruminal são encontradas em rações que utilizam farelo de soja como fonte de proteína, independentemente do nível de fibra, sendo observado valor médio de $0,18 \mathrm{mg}$ de $\mathrm{N}-\mathrm{NH}_{3} / \mathrm{mL}$ de líquido ruminal. Com essas características químicas, essas rações proporcionam maiores taxas de fermentação ruminal. Os valores mínimos da concentração de $\mathrm{N}-\mathrm{NH}_{3}$ no líquido ruminal não são limitantes para o crescimento microbiano em nenhuma das rações experimentais.

O menor valor de pH no líquido ruminal é encontrado nas rações com baixa fibra, obtendo-se valor médio de 6,27. Os valores mínimos de pH no líquido ruminal não são limitantes para o crescimento microbiano e para a digestão ruminal em nenhuma das rações experimentais.

\section{Literatura Citada}

CECAVA, M.J.; MERCHEN, N.R.; BERGER, L.L. et al. Effect of energy level and feeding frequency on site of digestion and postruminal nutrient flows in steers. Journal of Dairy Science, v.73, p.2470-2479, 1990.

CECAVA, M.J.; MERCHEN, N.R.; BERGER, L.L. et al. Effects of dietary energy level and protein source on nutrient digestion and ruminal nitrogen metabolism in steers. Journal of Animal Science, v.69, p.2230-2243, 1991.

CHURCH, D.C. The ruminant animal digestive physiology and nutrition. Englewood Cliffs: O \& Books Inc., 1988. 564p.

CHRISTENSEN, R.A.; CAMERON, M.R.; KLUSMEYER, T.H. et al. Influence of amount and degradability of dietary protein on nitrogen utilization by dairy cows. Journal of Dairy Science, v.76, p.3497-3513, 1993.

COELHO DA SILVA, J.F.; LEÃO, M.I. Fundamentos de nutrição dos ruminantes. Piracicaba: Livroceres, 1979. 380p.

FORBES, J.M.; FRANCE, J. Quantitative aspects of ruminant digestion and metabolism. Wallingford:CAB International, 1993. 515p.

GOMES, F.P. Curso de estatística experimental. 13.ed. Piracicaba: Escola Superior de Agricultura “Luiz de Queiroz”, 1990. 468p.

HOOVER, W.H.; STOKES, S.R. Balancing carbohydrates and proteins for optimum rumen microbial yield. Journal of Dairy Science, v.74, p.3630-3644, 1991.
LEÃO, M.I.; COELHO DA SILVA, J.F. Técnica de fistulação de abomaso em bezerros. In: CONGRESSO BRASILEIRO DE ZOOTECNIA, 1. REUNIÃO ANNUAL DA SOCIEDADE BRASILEIRA DE ZOOTECNIA, 17., Fortaleza, 1980. Anais... Fortaleza:Sociedade Brasileira de Zootecnia, 1980. p.37.

McDONALD, P.; EDWARDS, R.; GREENHALGH, J.F.D. Nutricion animal. 4.ed. Zaragoza: Acribia, 1993. 571p.

NATIONAL RESEARCH COUNCIL - NRC. Nutrient requeriments of beef cattle. Washington, D.C.:National Academy of Science, 1984. 90p.

NATIONAL RESEARCH COUNCIL - NRC. Nutrient requeriments of dairy cattle. Washington, D.C.: National Academy of Science, 1989. 157p.

ORSKOV, E.R. Nutrición proteica de los ruminantes. Zaragoza: Acribia, 1988. 178p.

ROBINSON, P.H.; McQUEEN, R.E. Influence of supplemental protein source and feeding frequency on rumen fermentation and performance in dairy cows. Journal of Dairy Science, v.77, p.1340-1353, 1994.

RODRIGUEZ, N.M. Importância da degradabilidade da proteína no rúmen para a formulação de rações para ruminantes. Cadernos Técnicos da Escola de Veterinária UFMG, n.1, p.27-45, 1986.

RUSSELL, J.B.; O’CONNOR, J.D.; FOX, D.G. et al. A net carbohydrate and protein system for evaluating cattle diets. I. Ruminal fermentation. Journal of Animal Science, v.70, p. 3551-61, 1992.

SHRIVER, B.J.; HOOVER, W.H.; SARGENT, J.P. et al. Fermentation of a high concentrate diet as affected by ruminal $\mathrm{pH}$ and digesta flow. Journal Dairy Science, v.69, p.413-419, 1986.

SILVA, D.J. Análise de alimentos (métodos químicos e biológicos). 2.ed. Viçosa, MG: Universidade Federal de Viçosa, 1990. 165p.

SLYTER, L.L.; SATTER, L.D.; DINIUS, D.A. Effect of ruminal ammonia concentration on nitrogen utilization by steers. Journal Animal Science, v.48, p.906-912, 1979.

SNIFFEN, C.J.; O’CONNOR, J.D.; Van SOEST, P.J. et al. A net carbohydrate and protein system for evaluating cattle diets. II. Carbohydrate and protein availability. Journal of Animal Science, v.70, p.3562-3577, 1992.

TITGEMEYER, E.C.; MERCHEN, N.R.; BERGER, L.L. et al. Evaluation of soybean meal, corn gluten meal, blood meal and fish meal as sources of nitrogen and amino acids disappearing from the small intestine of steers. Journal of Animal Science, v.67, p.262-275, 1989.

UNIVERSIDADE FEDERAL DE VIÇOSA - UFV. SAEG Sistema de análises estatísticas e genética. Viçosa, MG, 1995. (Versão 5.0).

Van SOEST, P.J. Nutritional ecology of the ruminants. Corvallis: O \& Books, 1982. 373p.

Recebido em: 15/01/03 Aceito em: 28/07/03 